\title{
The Utilization of User Fees to Subsidize Greenhouse and Growth Chamber Facilities at Public and Land Grant Universities
}

\author{
Kennedy Mayfield-Smith ${ }^{1}$, Alexa J. Lamm ${ }^{1}$, \\ and Robert N. Stougaard ${ }^{2}$
}

\begin{abstract}
ADDITIONAL INDEX WORDS. deferred maintenance, greenhouse management, growth chamber management

Summary. Greenhouse and growth chamber operating and maintenance costs continue to escalate while budgets remain stagnant. As a result, many universities struggle to find the necessary funds for the maintenance, repair, and replacement of basic research infrastructure needs. A survey was conducted to develop an understanding of how user fee systems contribute to funding stability, and how they are designed and managed in support of greenhouse and growth chamber facilities at colleges of agriculture throughout the United States. Where user fees have been implemented, the majority of greenhouse and growth chamber facilities are managed centrally, and are administered by agricultural experiment station (AES) directors or facility managers. Regardless of the administrative authority, most systems use an advisory committee to set fee schedules and determine policies. The majority of user fees are allocated back to the specific facility, with the majority of funds in general used to help pay for indirect expenses. The findings also indicate that user fees make more efficient use of space by providing faculty with a financial incentive to minimize their project area and to conduct experiments quickly.
\end{abstract}

G reenhouses and growth chambers are among the most important and widely used research facilities at colleges and universities, supporting projects across a range of disciplines and departments. Greenhouse and growth chamber research encompass experiments designed to investigate plants grown for amenities, food, habitat restoration, and pharmaceutical and nutraceutical applications, while also serving as a valuable teaching resource. These facilities are critical for developing new plant cultivars, optimizing yield-enhancing management practices, and understanding the fundamentals of plant growth and development.

\footnotetext{
Received for publication 17 Nov. 2020. Accepted for publication 10 Mar. 2021.

Published online 30 April 2021.

${ }^{1}$ Department of Agricultural Leadership, Education and Communication, University of Georgia, 135 Four Towers, Athens, GA 30602

${ }^{2}$ Office of the Associate Dean for Research, 109 Conner Hall, University of Georgia, Athens, GA 30602

K.M.-S. is the corresponding author. E-mail: kam42462@uga.edu.

This is an open access article distributed under the CC BY-NC-ND license (https://creativecommons. org/licenses/by-nc-nd/4.0/).

https://doi.org/10.21273/HORTTECH04761-20
}

Today's modern greenhouses and growth chambers are advanced plant growth facilities with precise environmental controls that allow faculty to conduct a wide range of important studies throughout the year. However, increased research space comes with increased repair costs, pushing many of the older facilities into a state of disrepair (Goldman and Williams, 2000; Sightlines, 2015). Some greenhouses are 40 to 60 years old and often fail to meet the basic requirements associated with standard greenhouse research and teaching.

Lack of sufficient funding has resulted in deferred maintenance issues throughout many colleges and universities, and threatens the operation of greenhouse and growth chamber facilities. Greenhouse, headhouse, and growth chamber space generally suffer from structural, environmental, and mechanical deficiencies, jeopardizing the integrity of experiments as well as the health and safety of faculty, staff, and students. The Association of Public and Land-grant Universities recently assessed capital infrastructure at 91 schools of agriculture and found an estimated $\$ 8$ billion in deferred maintenance costs (Sightlines, 2015).
Greenhouses, as a building category, had an average deferred maintenance of more than $\$ 65 / \mathrm{ft}^{2}$ gross. The overall situation is expected to worsen, because only about $20 \%$ of the surveyed schools invest at levels that would at least stabilize the backlog of deferred maintenance. Adding to this problem are the ever-increasing operating expenses for conducting research. Variable inputs such as pots and flats, soil and growth media, and fertilizer and crop protection products are all fundamental to conducting greenhouse and growth chamber research, but are costly. In addition, there are the costs associated with equipment repair and replacement, labor, and utilities.

In short, operating and maintenance costs continue to escalate while budgets stay stagnant. As a result, many universities struggle to find the necessary funds for the maintenance, repair, and replacement of basic research infrastructure needs. Facility expenses are typically categorized as indirect and direct costs. A direct cost is any expense that can be identified specifically with a particular project, program, or activity with a high degree of accuracy (National Institutes of Health, 2017). Examples of direct costs include materials or products used for a specific experiment, research personnel, and graduate student assistantships. Direct costs are known in advance and are accounted for during the research proposal process (National Institutes of Health, 2017). Indirect costs are those expenses not readily tied to a specific project or organizational activity (May and Sarson, 1999). Indirect costs can be further divided into administrative and facility expenses (Goldman and Williams, 2000). The administrative component includes salaries and expenses for general and departmental administration, whereas facilities expenses include costs for operation, maintenance, and repair and renovation of buildings and equipment. Typically, utility costs are included because it is difficult to assign these expenses to individual research projects.

Indirect costs are often grouped into common pools and are charged to research projects to benefit overall research objectives through an allocation process or indirect cost rate $(\mathrm{Na}$ tional Institutes of Health, 2017). However, many agencies either limit or prohibit inclusion of indirect costs 
in research proposals. This situation necessitates that indirect costs be addressed by state appropriations. Inasmuch as state support for higher education has been in decline, administrators are searching for alternative sources of funding to maintain and create facilities supportive of cuttingedge research (Guerrero et al., 2019; Miller et al., 2014).

Some colleges and universities have adopted the concept of user fees as a way of helping to defray the costs associated with the operation and maintenance of greenhouse and growth chamber facilities. However, the extent to which user fees help to improve financial stability and address deferred maintenance issues is unknown. This survey was undertaken to gain an understanding of how user fee systems contribute to funding stability, how user fees are designed, and how user fees are implemented and managed in support of greenhouse and growth chamber facilities.

\section{Materials and methods}

Our study used a basic quantitative survey research design to address the research objectives (Babbie, 2010). The research was conducted with the intent of identifying how user fees were being implemented at a range of universities to inform the development of a cost-based fee system at universities that may not have one currently in place.

Study population. The target population for the study consisted of AES directors at public and land-grant universities in the United States. Potential respondents were identified through an AES research director list maintained by the National Information Management and Support System.

InSTRUMENTATION. The survey was initially distributed to an expert panel for face and construct validity (Haynes et al., 1995). Construct validity was used to evaluate how well the survey measured each research objective (Setia, 2017). Face validity was used to ensure the instrument contained relevant questions (Setia, 2017). These measures ensure that the type of questions being asked align directly with the purpose of the study. The expert panel included staff, faculty, and administrators specializing in research facility affairs, horticulture, greenhouse management, and growth chamber management. After the expert panel review, minor changes were made to the instrument. The research protocol was then reviewed and approved by the University of Georgia Institutional Review Board before study initiation. The survey was prepared for online distribution using an online survey platform (Qualtrics, Provo, UT) and consisted of the same set of 10 questions for each facility type. The survey questions were developed to determine how greenhouse and growth chamber user fees are designed, implemented, and managed at colleges of agriculture.

After confirming that the institution did assess user fees, the respondents were asked how long the policy had been in effect (how long has a user fee policy been in place?). Answers were assigned into one of four categories, based on the time frame, and then expressed as a percentage of the total respondent pool. The four categories included less than 10 years, 10 to 20 years, 21 to 30 years, and unknown. Respondents were then asked what percentage of greenhouse and growth chamber facilities were managed by various administrative units (what percent of your research facilities are administered by the following?). Possible responses included provost, AES director, center director, department head, facilities manager, or other as possible answers. The response format was a constant sum, with all numbers needing to total $100 \%$ to continue.

In line with our research objectives, respondents were asked to identify which entity determines fee schedules (who determines user fee rates?). Possible responses included provost, AES director, center director, department head, facilities manager, or advisory committee. In a related question, respondents were asked whether user fee rates were uniform or variable (are user fees uniform throughout the system or do fees vary by campus/location?). Answers were assigned into one of two categories, uniform or variable, and then expressed as a percentage of the total respondent pool.

Next, respondents were asked to indicate how greenhouse and growth chamber fees were assessed (how are user fees assessed?). Possible response options included type/quality of facility, duration of the experiment, area used, services rendered, and other. Respondents were asked to check all that applied. Because area used is a key factor in determining both greenhouse and growth chamber fee schedules, respondents were asked to indicate how research space was allocated (how is research space allocated?) through a check-all system. Possible response options included project type, project needs, duration of the experiment, first come first served, and other. Fees schedules are also a function of the services provided. Respondents were asked to indicate which services were related to the user fee (what services are associated with the user fee?). The six possible responses included basic materials, study establishment, study maintenance, greenhouse/growth chamber maintenance, data collection, or other. Respondents were asked to check all that applied. Respondents were asked to indicate how the revenues from facility fee charges were allocated to different administrative units (how are the revenues from facility user fees allocated?). Possible responses included provost, AES director, center director, department head, facilities manager, or other. The response format was a constant sum, with all numbers needing to total $100 \%$ to continue.

Ultimately, the fees collected should be used to support the research facility in question. Respondents were asked how user fees are reinvested into each facility type (what percentage of costs are recovered with greenhouse user fees for each of the following categories?). Possible expense categories included facility operating and maintenance, repair and replacement, direct material costs, personnel, and other. The response format was a constant sum, with all numbers needing to total $100 \%$ to continue. Answers were assigned into one of five categories based on the percentage range, and were then expressed as a percentage of the total respondent pool. The five percentage categories included $0 \%, 1 \%$ to $25 \%$, $26 \%$ to $50 \%, 51 \%$ to $75 \%$, and $76 \%$ to $100 \%$.

In addition to these standard statistical measures, during the survey respondents had the opportunity to 
describe any additional ways that faculty benefit from user fee charges through free-answer responses and pdf attachment opportunities.

Data collection. The survey was distributed using the tailored design method (Dillman et al., 2014). A presurvey notice was mailed from the assistant dean of research at the University of Georgia to 80 potential respondents consisting of AES directors. Customized invitations describing the research purpose and links to take the survey were e-mailed the next day. Seven days after sending the survey invitations, nonrespondents were sent an online reminder. Seven days later, nonrespondents were sent an additional reminder of the impending survey close date. Two days later, a final reminder was sent to all nonrespondents with the survey closing time and date.

Data Analysis. Data were analyzed descriptively using statistical software (SPSS Statistics version 25; IBM Corp., Armonk, NY). Missing information for particular variables were excluded on an analysis-by-analysis basis. The data cleaning process caused slight variation in the effective sample size for each analysis and is noted throughout the results.

\section{Results}

SurVey DEMOgRaphics AND USER FEE POLICY AGE. Of the 80 surveys distributed, 36 institutions responded, resulting in a $45 \%$ response rate. Respondents represent 26 states and three U.S. territories. Overall, the assessment of user fees for greenhouses is more common than for growth chambers. Of 36 respondents, 20 indicated that they charge fees for using greenhouse facilities, whereas 15 institutions assess fees for the use of growth chamber facilities. Greenhouse fee assessment has a longer history as well, with $45 \%$ of respondents indicating that fee systems have been in place for 10 to 20 years (Table 1 ). In comparison, growth chamber user fees seem to be a relatively new concept, with $47 \%$ of the policies being initiated within the past 10 years

Administration. The majority of greenhouses are administered by AES directors. Greenhouse facilities managers are the second most common administrative lead (Table 2).
This is followed by administrative combinations, where department heads share responsibility with different unit leadership positions. In addition, there are a few examples where department heads serve as the sole administrative lead. These results indicate that the majority of greenhouse facilities are administered centrally. However, user fees also are assessed at independently managed greenhouses.

Similar to greenhouses, growth chamber facilities are most often managed by AES directors and facilities managers. Both administrative types are cited at $33 \%$, which again indicates a centrally managed system. Administrative combinations are also common, being identified in $20 \%$ of the cases. In all instances, the administrative combination includes the facilities manager along with different unit leadership positions. In a few instances, growth chambers are managed by specific departments, and in some cases, by individual faculty.

FeE DETERmination. Greenhouse fees are determined by the AES director in $35 \%$ of the cases (Table 3 ). This is closely followed by advisory committees at $25 \%$. Facility managers and administrative combinations determine fees in $15 \%$ of the cases. The combination systems represent a hybrid of different leadership units that determine the fee rate jointly. And in one instance, fees are determined by the provost. These results also reflect a centralized greenhouse management system. Within individual institutions,

Table 1. Reported average length of time a user fee policy has been in place for greenhouse and growth chamber facilities at public and grant universities, expressed as percentage of respondents $(n=35)$.

\begin{tabular}{lcccc}
\hline & \multicolumn{4}{c}{ Policy length (years) } \\
\cline { 2 - 5 } & $<10$ & 10-20 & 21-30 & Unknown \\
\cline { 2 - 5 } Facility type & & Survey responses (\% respondents) \\
\hline Greenhouse & 35 & 45 & 10 & 10 \\
Growth chamber & 47 & 33 & 13 & 7 \\
\hline
\end{tabular}

Table 2. Percentage of primary facility administration choices for greenhouse and growth chamber research facilities in an online survey (Qualtrics, Provo, $\mathrm{UT})(\mathrm{n}=35)$.

\begin{tabular}{lcccc}
\hline & \multicolumn{3}{c}{ Survey responses (\% respondents) } \\
\cline { 2 - 5 } Facility type & $\begin{array}{c}\text { Agricultural expt. } \\
\text { station director }\end{array}$ & $\begin{array}{l}\text { Facility } \\
\text { manager }\end{array}$ & Combination $^{\mathrm{z}}$ & $\begin{array}{c}\text { Department } \\
\text { head }\end{array}$ \\
\hline Greenhouse & 45 & 25 & 20 & 10 \\
Growth chamber & 33 & 33 & 20 & 13 \\
\hline
\end{tabular}

greenhouse fees vary in $50 \%$ of the cases. Fee variation occurs as a result of differing locations and administrative leadership, as well as the quality of the greenhouse space. Greenhouse qualities that may affect cost include increased environmental control, advanced technology, and increased expert labor.

Growth chamber fee schedules are determined in a manner similar to that of greenhouses, with advisory committees $(40 \%)$ and AES directors (33\%) most often setting rates (Table 3 ). In contrast to greenhouse systems, facility managers are seldom responsible for setting growth chamber fees. So, although facility managers often administer growth chamber facilities, the data indicate they rely on advisory committees to determine fee schedules. Growth chamber fees are also determined at a low frequency by provosts and department heads, and one institution uses a facilities service center to determine fees. Growth chamber fee schedule assessments are pplied consistently throughout an inthe cases, but vary stime depending on ownership and quality of the growth chamber.

Fee assessment. The most important factor in determining greenhouse user fees is the area used by the experiment (e.g., bench, bay, section). Duration of the experiment and services rendered are also important, with both being cited by $65 \%$ of the respondents (Fig. 1). As a result, greenhouse fee structures are commonly

${ }^{\mathrm{z}} \mathrm{A}$ combination of multiple leadership bodies. 
Table 3. Primary fee determiners for greenhouse and growth chambers expressed as a percentage of respondents, including university provost, agricultural experiment station (AES) director, department head, research facility manager, facility advisory committee, a combination, or other $(n=35)$.

\begin{tabular}{|c|c|c|c|c|c|c|c|}
\hline \multirow[b]{2}{*}{ Facility type } & \multicolumn{7}{|c|}{ Survey responses (\% respondents) } \\
\hline & Provost & $\begin{array}{c}\text { AES } \\
\text { director }\end{array}$ & $\begin{array}{c}\text { Department } \\
\text { head }\end{array}$ & $\begin{array}{l}\text { Facilities } \\
\text { manager }\end{array}$ & $\begin{array}{c}\text { Advisory } \\
\text { committee }\end{array}$ & Combination $^{\mathrm{z}}$ & Other \\
\hline Greenhouse & 5 & 35 & 0 & 15 & 25 & 15 & 5 \\
\hline
\end{tabular}

${ }^{\mathrm{z}} \mathrm{A}$ combination of multiple leadership bodies.

expressed in dollars/area/month, with other fees being incurred if additional services are provided. Another of greenhouse facility. Greenhouse facilities can be quite variable, and so, too, the fees that are assessed. An extreme example would be to compare fees for a plastic-covered hoop house vs. a glasshouse structure with environmental controls and supplemental lighting. In addition to having differing research capabilities, each has different maintenance and operating costs. Other considerations mentioned include whether the user was external or internal to the administering unit.

When asked how growth chamber fees were assessed, area used and duration of the experiment were equally important and were the primary considerations affecting fee assessment (Fig. 1). As such, growth chamber fee schedules are calculated in a manner similar to that of greenhouses and are also expressed in dollars/area/month. The type and quality of the facility is also an important consideration, but it is not as critical as it is for greenhouses. This may be a result of the greater important factor is the quality or type

overall similarity in type and quality of growth chamber facilities relative to greenhouses. Fees are also assessed for services provided, but this type of charge is less common than it is for greenhouse facilities. Other fee assessments are based on whether growth chamber use is internal or external to the administrative unit.

Space allocation. Greenhouse space is typically measured and allocated by square feet or bench space. Space is prioritized based on project type as well as project needs and importance (Fig. 2). Project type considers whether the space is being used for research, teaching, extension, or by an external user, whereas project needs include items such as biosafety level containment, photoperiod, and study size. Greenhouse space is also allocated on a first-come-first-served basis as well as by project duration. Other allocation methods include the use of an oversight committee. In some instances, user fees are being assessed, yet greenhouse space is allocated to specific projects based on historical usage. So, although user fees can help contribute to fair space allocation among faculty,

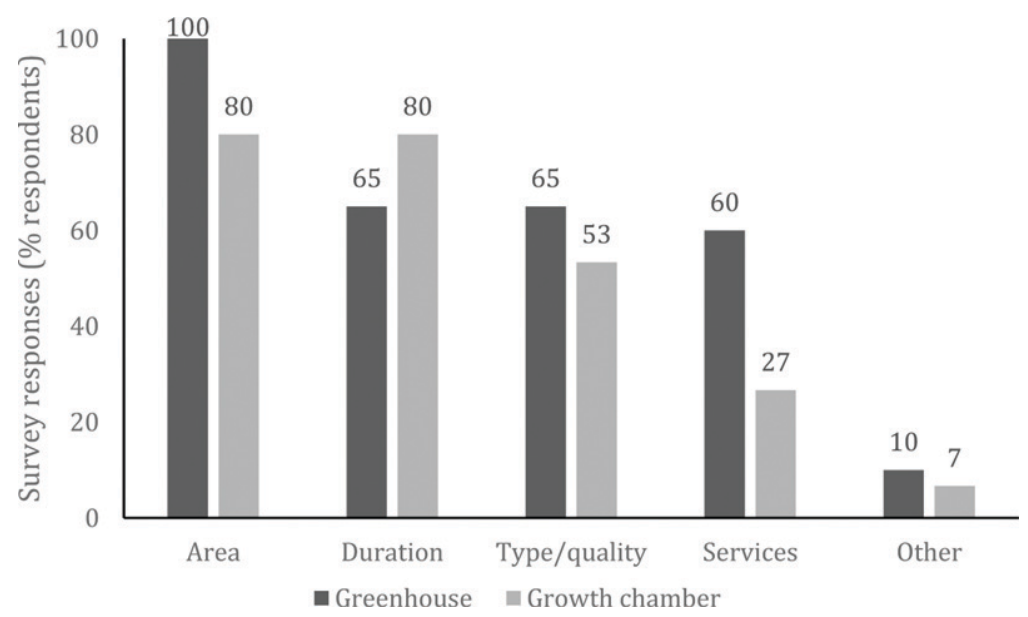

Fig. 1. Representation of the primary fee assessment criteria used to determine greenhouse and growth chamber fee schedules. Fee schedules are used as guidelines to determine how and when facility users are charged. space assignments can be regulated by other policy directives. Growth chamber research space is allocated based on project type, first come first served, project needs, and project duration, respectively (Fig. 2). Growth chamber space is also allocated based on input from advisory committees as well as on ownership of the unit. In the latter case, ownership is typically an individual faculty member or a department.

SERVICES INCLUDED. For greenhouse services, respondents selected greenhouse maintenance most often. Greenhouse maintenance could include general repair, replacement of lights and cooling pads, environmental monitoring, and cleaning of facilities. Study maintenance (fertilization, irrigation, pest management) as well as the provision of basic materials (potting media, stakes, and fertilizer) are other important benefits associated with greenhouse user fees (Fig. 3). Help with establishing studies and assistance with data collection are considered less important.

Similar trends are noted for growth chamber facilities. Growth chamber maintenance is the most important service, and could include changing lights, monitoring the environment, making general repairs, and cleaning. Basic materials and study maintenance are secondary in importance, whereas study establishment and data collection are least important (Fig. 3).

Revenue allocation. The majority of greenhouse user fees are directed back to the greenhouse facility, followed by AES directors and departments, respectively (Table 4). Other systems include allocations to an advisory committee as well as a shared allocation between administrative unit leaders. For growth chambers, the majority of the revenues are also directed back to the growth chamber facility. Less frequently, revenue is allotted to the administering department. Other scenarios include funds 


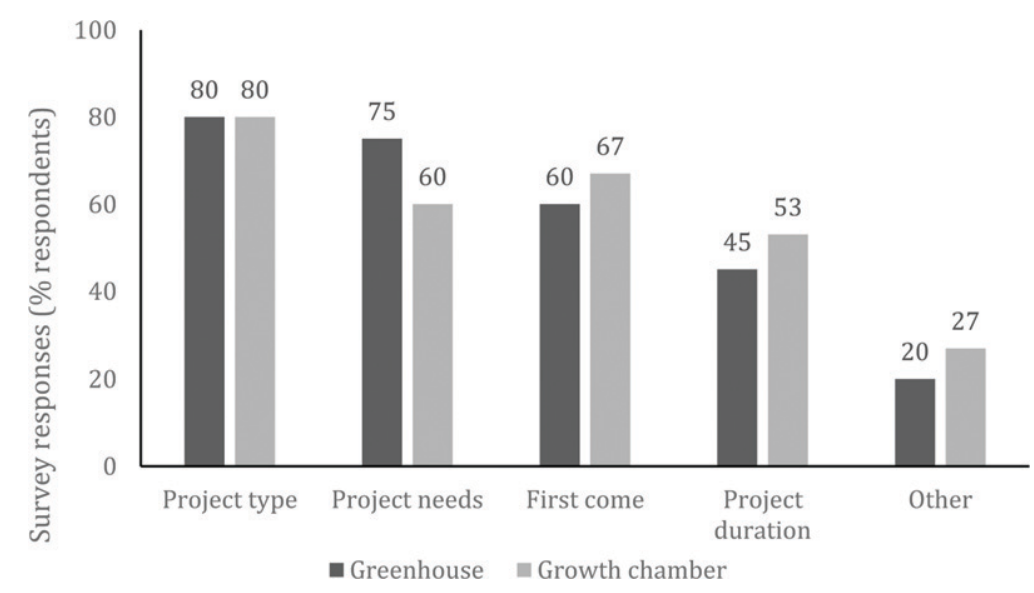

Fig. 2. In addition to the implementation of a fee schedule, universities set specific space allocation methods to determine how space is divided among facility users based on different aspects of their projects.

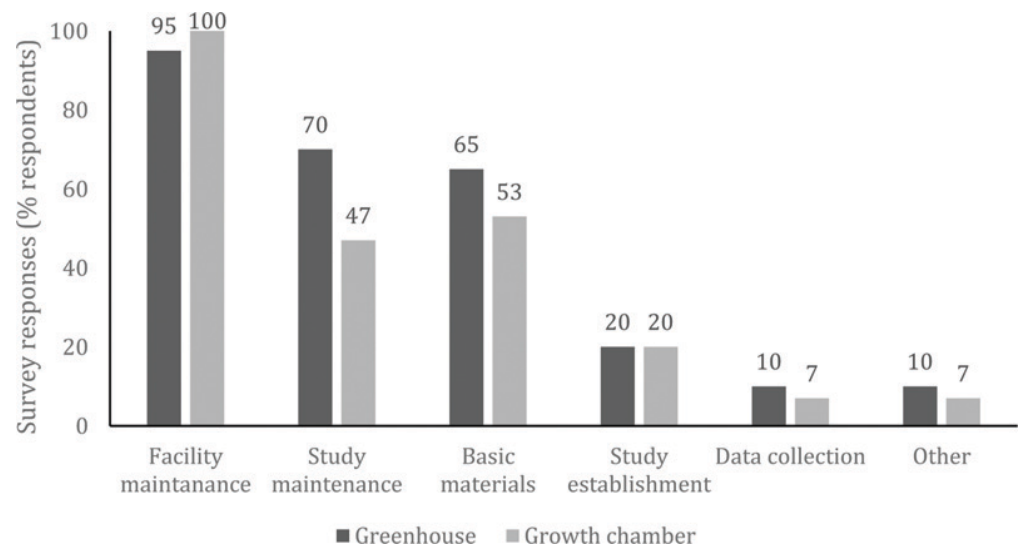

Fig. 3. A multitude of services may be provided by research facilities at free or reduced costs. The introduction of user fees allows facility management to provide these primary services.

assigned to a combination of administrative partners, returned to a centralized management body such as an advisory committee or to the plant growth facilities core service center.

Percentage of COSTS ReCOVERED. The main impetus for establishing user fees is to provide funds to help maintain the research infrastructure. In this regard, the survey results demonstrate that greenhouse user fees are

used primarily to help defray expenses associated with greenhouse maintenance and operation as well as repair and replacement costs (Table 5). Secondarily, the fees are used toward direct material expenses and to help defray labor costs. In fact, $50 \%$ to $55 \%$ of the respondents do not attempt to recover costs in these latter two categories. However, of those institutions that do recover direct material costs,

Table 4. Primary recipients of greenhouse and growth chamber user fee revenue allocation as represented through a survey (Qualtrics, Provo, UT). Recipients include the actual research facility, Agricultural Experiment Station (AES) director, department, and other $(\mathbf{n}=35)$.

\begin{tabular}{lcccc}
\hline & \multicolumn{4}{c}{ Survey responses (\%) } \\
\cline { 2 - 5 } Facility type & Actual facility & AES director & Department & Other \\
\hline Greenhouse & 50 & 20 & 20 & 10 \\
Growth chamber & 47 & 7 & 27 & 20 \\
\hline
\end{tabular}

several recoup more than $50 \%$ of those expenses.

Likewise, the majority of growth chamber fees are directed to maintenance and operation, and repair and replacement expenses (Table 6). This makes sense inasmuch as growth chamber maintenance is viewed as the most important service associated with fee assessments. A smaller percentage of fees is allocated to material costs and personnel expenses. Relative to greenhouse expenses, growth chamber user fees tend to recover a greater percentage of total costs.

\section{Results and discussion}

The survey results revealed the majority of greenhouse and growth chamber facilities were managed centrally and were administered by AES directors or facility managers. A centralized system requires a facility management approach that treats space as a shared asset across multiple researchers and departments. Overall, this provides for efficiencies and avoids duplication of critical facility functions, personnel, and equipment. User fees, in particular, help to use space more efficiently by providing faculty with a financial incentive to minimize their project area and to conduct experiments quickly.

Regardless of the administrative authority, most systems used an advisory committee to set fee schedules and determine policies. When an advisory committee functions well, it can provide a broad base for input, a sense of ownership by the users, and transparency with respect to how funds are generated and spent. Although these factors make the assessment of user fees more appealing, faculty should also realize that user fees benefit their research programs. Overall, faculty acquire improved research capabilities by having access to better facilities, support, and equipment. In both facility types, operation and maintenance, and repair and replacement were considered the most important services provided by user fees. As a result, environmental controls were enhanced, equipment breakdowns were reduced, and overall quality was improved, resulting in greater uniformity among facilities. Several institutions also noted the benefits of having a dedicated staff to maintain plant growth facilities around the clock while also providing advice and 
Table 5. Percentage of greenhouse costs recovered with the implementation of user fees by category based on percentage of respondents $(n=35)$.

\begin{tabular}{lccccc}
\hline & \multicolumn{5}{c}{ Costs recovered (\%) } \\
\cline { 2 - 6 } Cost category & $\mathbf{0}$ & $\mathbf{1 - 2 5}$ & $\mathbf{2 6 - 5 0}$ & $\mathbf{5 1 - 7 5}$ & $\mathbf{7 6 - 1 0 0}$ \\
\hline Operation and maintenance & 20 & 25 & 40 & 10 & 5 \\
Repair and replacement & 20 & 40 & 35 & 5 & 0 \\
Direct material costs & 50 & 5 & 25 & 5 & 15 \\
Personnel & $\mathbf{5 5}$ & 25 & 15 & 0 & 5 \\
\hline
\end{tabular}

Table 6. Percentage of growth chamber costs recovered with the implementation of a user fee by category based on percentage of respondents $(n=35)$.

\begin{tabular}{lccccc}
\hline & \multicolumn{5}{c}{ Costs recovered (\%) } \\
\cline { 2 - 6 } Cost category & $\mathbf{0}$ & $\mathbf{1 - 2 5}$ & $\mathbf{2 6 - 5 0}$ & $\mathbf{5 1 - 7 5}$ & $\mathbf{7 6 - 1 0 0}$ \\
\hline Operation and maintenance & 20 & 33 & 27 & 7 & 13 \\
Repair and replacement & 27 & 27 & 20 & 7 & 20 \\
Direct material costs & 67 & 0 & 13 & 7 & 13 \\
Personnel & 60 & 20 & 13 & 0 & 7 \\
\hline
\end{tabular}

assistance with designing and conducting experiments.

The majority of user fees were allocated back to each specific facility. Upon return, the funds were generally used to help pay for indirect expenses. As a result, respondents noted that facility maintenance, operation, and repair and replacement costs were most often cited as where user fees were directed. Communication should occur often so that faculty members can clearly see the benefits of their financial contributions toward improving the research facility they are using, and, as a consequence, their ability to
Dillman, D.A., J.D. Smyth, and L.M. Christian. 2014. Internet, mail, and mixed-mode surveys: The tailored design method. Wiley, Hoboken, NJ.

Goldman, C.A. and T. Williams. 2000. Paying for university research facilities and administration. 13 Dec. 2020. <https:// www.rand.org/pubs/monograph_reports/ MRl135-1.html>.

Guerrero, M., D. Urbano, and F. Herrera. 2019. Innovation practices in emerging economies: Do university partnerships matter? J. Technol. Transf. 44:615-646, doi: 10.1007/s10961-017-9578-8.

Haynes, S.N., D. Richard, and E.S. Kubany. 1995. Content validity in psychological assessment: A functional approach to concepts and methods. Psychol. Assess. 7:238-247, doi: 10.1037/1040-3590.7.3.238.

May, R.M. and S.C. Sarson. 1999. Revealing the hidden costs of research. $\mathrm{Na}$ ture 398:457-459, doi: 10.1038/18961.

Miller, K., R. McAdam, and M. McAdam. 2014. The changing university business model: A stakeholder perspective. R \& D Mgt. 44 (3):265-287, doi: 10.1111/radm.12064.

National Institutes of Health. 2017. Understanding indirect costs. 18 May 2020. <https://www.niaid.nih.gov/grantscontracts/understanding-indirect-costs $>$.

Setia, M.S. 2017. Methodology series module 10: Qualitative health research. Indian J. Dermatol. 62:367, doi: 10.4103/ijd.IJD_290_17.

Sightlines. 2015. A national study of capital infrastructure \& deferred maintenance at schools of agriculture. 14 Jan. 2021. $<$ https://www.aplu.org/library/a-nationalstudy-of-capital-infrastructure-deferredmaintenance-at-schools-of-agriculture/file $>$. 